\title{
A Genetic Variant rs10251977 in Long Non-coding RNA EGFR-AS1 Creates a New Binding Site for miR- 891b and Modulates the Expression of EGFR A/D Isoforms
}

\section{Dhamodharan Shankar}

Dr. ALM PG Institute of Basic Medical Sciences, University of Madras

\section{Rose Mathew}

Dr. ALM PG Institute of Basic Medical Sciences, University of Madras

\section{Sundaram Reddy Chakkarappan}

Dr. ALM PG Institute of Basic Medical Sciences, University of Madras Uma Dharshini Karuppiah Vijayamuthuramalingam

Dr. ALM PG Institute of Basic Medical Sciences, University of Madras

\section{Arulmurugan Ramalingam}

Royapettah Government Hospital \& Kilpauk Medical College

\section{Subbiah Shanmugam}

Royapettah Government Hospital \& Kilpauk Medical College

Inoue Ituro

National Institute of Genetics

Munirajan Arasambattu ( $\square$ akmunirajan@gmail.com )

Dr. ALM PG Institute of Basic Medical Sciences, University of Madras

\section{Research Article}

Keywords: HNSCC, EGFR, rs10251977, EGFR-AS1, miR-891b

Posted Date: December 31st, 2020

DOI: https://doi.org/10.21203/rs.3.rs-136285/v1

License: (c) (i) This work is licensed under a Creative Commons Attribution 4.0 International License. Read Full License

Version of Record: A version of this preprint was published at Scientific Reports on April 22nd, 2021. See the published version at https://doi.org/10.1038/s41598-021-88161-3. 



\section{A genetic variant $r$ s10251977 in long non-coding RNA EGFR-AS1}

2 creates a new binding site for miR-891b and modulates the expression of

3 EGFR A/D isoforms

4 Shankar Dhamodharan ${ }^{1,+}$, Mathew Maria Rose ${ }^{1,+}$, Reddy Chakkarappan Sundaram ${ }^{1,4}$, Karuppiah

5 Vijayamuthuramalingam Uma Dharshini ${ }^{1}$, Ramalingam Arulmurugan ${ }^{2}$, Shanmugam Subbiah ${ }^{2}$,

6 Ituro Inoue ${ }^{3}$, Arasambattu Kannan Munirajan ${ }^{1, *}$.

$7{ }^{1}$ Department of Genetics, Dr. ALM PG Institute of Basic Medical Sciences, University of

8 Madras, Taramani Campus, Chennai-600 113, India.

$9{ }^{2}$ Center for Oncology, Royapettah Government Hospital \& Kilpauk Medical College, 10 Royapettah, Chennai-600 014, India.

$11{ }^{3}$ Division of Human genetics, National Institute of Genetics, Mishima- 411-8540, Japan

$12{ }^{4}$ Department of Health Research - Multi Disciplinary Research Unit (DHR-MRU), Dr. ALM PG

13 Institute of Basic Medical Sciences, University of Madras, Taramani Campus, Chennai 14600 113,India.

$15+$ These authors contributed equally to this work

16 *orrespondence to:

17 Arasambattu Kannan Munirajan, $\mathrm{PhD}$

18 Department of Genetics

19 Dr. ALM PG Institute of Basic Medical Sciences

20 University of Madras, Taramani Campus

21 Chennai - 600113, India.

22 Phone: +91-44-24547064, Fax: +91-44-24540709

23 E-mail: akmunirajan@gmail.com; akmunirajan@unom.ac.in. 
Abstract:

Tyrosine kinase inhibitor (TKI) is one of the effective chemo-preventive approaches against tumors that deregulate EGFR pathway. About $80 \%$ of HNSCC patients overexpress 33 EGFR, making TKI an effective treatment against this cancer. Recently a synonymous variant rs10251977 in exon 20 of EGFR reported to act as a prognostic marker in HNSCC. Analysis of this germline variant in blood samples of oral cancer patients showed a similar frequency in cases and controls. Further, in-silico analysis showed that this polymorphism creates binding site for miR-891b in EGFR-AS1. The EGFR-AS1 expression modulates the EGFR A/D isoforms through alternative splicing. Our bioinformatic analysis showed enrichment of alternative splicing marks H3K36me 3 and presence of a few intronic polyA sites spanning around exon $15 \mathrm{a}$ and $15 \mathrm{~b}$ of EGFR facilitating the skipping of exon $15 \mathrm{~b}$ and thereby promoting the splicing of EGFR-A isoform. In addition, the presence of PTBP1 binding site in EGFR and EGFR-AS1 enhances the expression of EGFR- A isoform by preventing the premature termination. Expression profiling of EGFR-AS1 along with miR-891b level and rs 10251977 polymorphism

44 status in oral cancer patients may be useful for targeted therapy.

45

KEYWORDS: HNSCC; EGFR; rs10251977; EGFR-AS1; miR-891b

47 


\section{Introduction}

59 Oral squamous cell carcinoma (OSCC) is one of the prevalent cancers worldwide. According to the GLOBOCAN 2018 report from India, cancer of lip, oral cavity is the top most cancer in men

61 and fourth most in women ${ }^{1}$ and often diagnosed in advanced stages, making it difficult for the therapeutic management. Tobacco chewing/smoking, alcohol consumption and infection with human papilloma virus (HPV) 16/18 are the major risk factors of OSCC ${ }^{2}$ In India, tobacco chewing with betel quid, slaked lime, and areca nut combined with smoking or drinking significantly increases the risk. Despite the advances in diagnosis and treatment the mortality rate of oral cancer patients has not markedly improved over the past three decades and the 5-year survival rate remains less than $50 \%$. Even with the advances in drug discovery and treatment against cancer, chemoresistance and tumor recurrence remains an obstacle for development of effective therapeutic management in the patients with $\mathrm{OSCC}^{3}$.

The etiology (58-90\%) of HNSCC is attributed with the aberrant activity of epidermal growth factor receptor (EGFR). It belongs to the family of receptor tyrosine kinases ErbB and plays an important role in cell cycle regulation, proliferation, cell migration and other physiological processes ${ }^{4}$. Overexpression of EGFR is observed in the early stages of the oral tumorigenesis and linked with the advanced stages of the tumor, thus it could serve as the effective drug target ${ }^{5}$. Though various evidences proved EGFR signalling is associated with progression of HNSCC, the effective treatment outcome is not achieved upon targeting EGFR with monoclonal antibodies and/or TKIs ${ }^{6}$. Therefore, it is essential to identify robust biomarkers for the success of targeted therapy.

Alternative splicing is a common mechanism employed by eukaryotic cells to create diversified proteomics profile from single gene ${ }^{7,8}$. This mechanism is common in receptor kinase family genes. EGFR generates a functionally important four splice variants through alternative splicing where $10.5 \mathrm{~kb}$ and $5.8 \mathrm{~kb}$ belongs to variant 1 class encoding $170 \mathrm{kDa}$ protein called isoform A. This variant will be generated by skipping of two exons 15a and 15b in EGFR, whereas $1.8 \mathrm{~kb}, 2.4 \mathrm{~kb}$ and $3.0 \mathrm{~kb}$ are three other isoforms formed from a read-through of a exonintron boundary and incorporation of alternate exons 15a and 15b, which encodes 60, 80 and 110 $\mathrm{kDa}$ proteins known as isoform $\mathrm{B}, \mathrm{C}$ and $\mathrm{D}$, respectively ${ }^{9,10}$. 
Currently, long non-coding RNAs (lncRNAs), a class of heterogeneous RNA molecules (>200 nt) with no protein-coding potential, has been identified as the prognostic marker in various cancer. The lncRNAs were aberrantly expressed in various cancers and play regulatory roles in several cellular pathways promoting proliferation, stem cell pluripotency, cellular reprogramming, cellular transformation, and tumorigenesis ${ }^{3}$. A recent study established the prognostic potential of EGFR-AS1 in tyrosine kinase inhibitors (TKIs) treatment and knockdown of EGFR-AS1 induced regression of squamous cell carcinoma of head and neck and aids in mediating a ligand addiction ${ }^{6}$.

Antisense non-coding transcript of EGFR locus (EGFR-AS1), a $2.8 \mathrm{~kb}$ transcript and was shown to promote the stability of its cis partner EGFR-A isoform ${ }^{11}$. However, the role of EGFRAS1 in maintaining the stability of EGFR-A isoform is yet to be studied in detail. This study is focussed on understanding the molecular consequence of a germline polymorphism $r s 10251977$ (c.2361G>A) in EGFR-AS1 that creates a binding site for miR-891b and modulates the stability of the EGFR-AS1. Additionally, we explored the role of EGFR-AS1 in the alternative splicing of EGFR A/D isoforms.

\section{Results}

\section{Screening of the germline variant $r$ s 10251977 in oral cancer patients of South Indian origin}

We screened for the variant $r s 10251977$ (c.2361G>A) in exon 20 of EGFR in 180 oral cancer patients with age and sex matched 184 cancer-free controls. The demographic details of both cases and controls were presented in Table 1. Oral cancer patients and control subjects' genotype frequencies were in agreement with Hardy-Weinberg equilibrium with p values 0.79 and 0.35 , respectively (Table 2). The genotype frequencies were found to be $40 \%$ (72/180) of GG, $47.2 \%$ $(85 / 180)$ of GA and $12.8 \%$ (23/180) of AA in oral cancer patients, 36.4\% (67/184) of GG, 50.5\% $(93 / 184)$ of GA and $13.1 \%$ (24/184) of AA in control subjects and no significant difference was found between cases and controls. A similar result was observed in dominant model (GA+AA vs $\mathrm{GG})$, recessive model ( $\mathrm{GG}+\mathrm{GA}$ vs $\mathrm{AA})$ and allelic model ( $\mathrm{G}$ vs $\mathrm{A})$ with an OR of $0.86(\mathrm{p}=0.55)$, $0.98(\mathrm{p}=0.93) \& 0.92(\mathrm{p}=0.64)$, respectively.

\section{EGFR-AS1 is overexpressed in OSCCs}

The EGFR-AS1 expression was analyzed in 48 oral tumor samples and 8 independent normal tissues by RT-qPCR (Table 3). A significant upregulation of EGFR-AS1 was observed in tumor 
tissues compared to that of normal tissues $(\mathrm{p}<0.001)$ (Figure 1a). The expression levels were correlated with clinic-pathological characteristics of the tumors, there is a trend in increased level of EGFR-AS1 was observed without any statistically significant association (Figure S1a). Interestingly, in tumors with GA and AA (N=25) genotypes, we noticed high level expression of EGFR-AS1 albeit with no statistical significance $(\mathrm{p}=0.653)$, and this could be due to the small sample size (Figure S1b).

\section{EGFR-AS1 in maintaining the level of EGFR A and D isoforms}

To know the functional relationship of EGFR-AS1 expression with EGFR and its isoforms, we analysed the relative expression levels of EGFR isoforms A and D and D/A ratio with reference to the expression level of EGFR-AS1. The tumor samples were stratified into two groups as EGFR-AS1 high and low expression groups based on the median values of EGFR-AS1 expression (Table 3). Tumors with expression level above median value is considered as high expression group and those with fold change below median value as low expression group. We observed a statistically significant difference in the expression level of EGFR-A form with reference to EGFR-AS1 level ( $\mathrm{p}<0.0001)$ and no significant difference was found for EGFR-D form (Figure 1b). But we observed significant difference in the EGFR isoform A and D levels in both the groups (Figure 1c), and found a significantly high level of EGFR isoform D transcript in low EGFR-AS1 expressing group compared to the high expression group $(\mathrm{p}=0.017)$ and this could be due to the modulation of RNA splicing. To address this, we carried out in-silico analysis to identify the EGFR-AS1/EGFR binding partners that has functional association with alternative splicing.

First, we predicted the binding partners of EGFR-AS1 by using online database lncRNAtor ${ }^{12}$. EGFR-AS1 showed significant mechanistic association with three RNA binding proteins FIP1, hnRNPU, and PTBP1, of which PTBP1 showed a significant association $\left(\mathrm{p}=8.43 \mathrm{E}^{-26}\right)$ (Figure S2a). To evaluate the binding of this alternative splicing factors in EGFR locus we used RBPmap online tool ${ }^{13}$ to predict the binding motif of the RNA binding proteins in both EGFRAS1 and region between exon 15 and 16 of EGFR gene and identified several consensus motif of PTBP1 (Table S1 and S2), suggesting the PTBP1 role in alternative splicing of EGFR-A isoform. To further support this hypothesis, we checked the binding partners for PTBP1 using STITCH online tool, and found that most of its interacting partners HNRNPK, HNRNPU, 
HNRNPA1, HNRNPA3, HNRNPD, HNRNPL and SNRPA were known to play a role in alternative splicing (Figure 2a).

Previous studies have shown that H3K36me3 plays an important role in exon skipping by recruiting alternative splicing factors ${ }^{14}$. We checked whether the H3K36me3 marks are present in EGFR region by using UCSC genome browser. Interestingly we found that enhanced H3K36me3 marks were present around the skipped region spanning the exon 15a and b region (Figure 2b), and to our surprise they also carried a few polyA sites spanning around region exon $15 \mathrm{a}$ leading to the skipping of exon $15 \mathrm{~b}$ and prevents premature termination thereby reducing EGFR-D isoform. EGFR-AS1 may act as a scaffold to recruit major alternative splicing factors in association with PTBP1 to bring exon skipping and promoting EGFR-A expression.

\section{EGFR variant rs10251977 creates miR-891b binding site in EGFR-AS1}

Apart from acting as scaffold, lncRNAs may also act as miRNA sponges in the cytoplasm. Tan et al., reported that the presence of minor allele in EGFR-AS1 decreased its steady state level $^{6}$ and this could be due to the miRNA sponging mediated degradation of lncRNA. We used a web-based tool called lncRNASNP2 to determine the functional impact of minor allele in EGFR-AS1.

The minor allele generates a new binding site for miR-891b (Figure 3a and 3b). We chose this miRNA and another miRNA, miR-138-5p (Figure 3c) which targets EGFR and remains unaffected by the presence of either major or minor allele for expression study (Figure S2b). Both the miRNAs targets EGFR-A isoform, as confirmed by TargetScan and miRwalk tools (Figure 3d). Gene Set Enrichment Analysis (GSEA) for miR-891b and miR-138-5p revealed that they are involved in pathways related to cancer and MAPK signaling pathway, respectively (Table S3 and S4).

\section{Correlation of EGFR-AS1 level with the miRNA level}

The expression levels of both miR-891b and miR-138-5p, were analyzed in 48 oral tumor tissues and 8 adjacent normal tissues and were found to be significantly downregulated in tumor tissues compared to that of normal tissues with a p-value of 0.03 and 0.047 , respectively (Figure $4 \mathrm{a} \&$ 4b). Tumors that over expressed miR-891b and miR-138-5p were found to have a significantly low level of EGFR-AS1 ( $\mathrm{p}=0.04$ and 0.02 , respectively) (Figure 4c \& 4d). The EGFR D/A isoforms ratio showed no statistically significant difference between high and low miRNA 
expression groups, but the tumors with overexpressed miRNAs showed a trend of increased D/A ratio (Figure S3a and 3b). When correlated with the expression level of EGFR-A, the tumors with an increased level of miR-891b had significantly low level of EGFR-A (p-value- 0.02) (Figure 4e) suggesting the possibility of ceRNA network operating in these tumors. Our results suggest that the presence of minor allele generates the binding site for miR-891b thereby switching the mechanism of EGFR-AS1 from a scaffold to miRNA sponge modulating the expression level of EGFR-A isoform.

\section{Discussions}

$E G F R$ is found to be frequently mutated and deregulated in multiple cancers, especially malignancies of epithelial origin in humans. Thus, tyrosine kinase inhibitors have been increased attention towards targeted therapy in cancers ${ }^{15-17}$. Various studies focused on EGFR variants conferring sensitivity towards TKI treatments. Recently Tan et al., identified a synonymous variant rs 10251977 (c.2361G $>\mathrm{A})$ present in exon 20 of EGFR having greater prognostic implication towards TKI treatments particularly in squamous cell carcinoma of head and neck ${ }^{6}$. In the current study the prevalence of this polymorphism is known to be $40 \%(72 / 180)$ of GG genotype, 47.2\% (85/180) of GA genotype and 12.8\% (23/180) of AA genotype among oral cancer patients with a minor allele frequency of 0.36 . This is consistent with the previous report where they found increased prevalence of the same polymorphism in head and neck cancer patients from South Indian origin with $61.24 \%$ and $13.95 \%$ of both GA and AA genotypes, respectively ${ }^{5}$. They also observed that the polymorphism had a significant risk association in cancer development. Several studies emphasized the prognostic significance of this EGFR variant in TKI response ${ }^{18-20}$, whereas the wild type genotype predicted to have a good prognosis in metastatic colorectal cancer $^{21}$. Interestingly, Koh et al., reported that this polymorphism is more prevalent in squamous cell carcinoma compared to that of adenocarcinoma of lung, and having a significant response for gefitinib treatment in patients who carries a wild type allele ${ }^{22}$. Previous study on this variant in advanced oesophageal squamous cell carcinoma recorded that patients with heterozygous genotype shows a poor response ${ }^{23}$. However, we did not observe any significant association of this polymorphism with cancer risk. The increased prevalence of this variant and its strong association with therapeutic response prompted us to explore its functional significance. The variant allele created a new binding site for miR-891b reducing the level of EGFR-AS1 and leading to increase in the EGFR D/A isoform ratio. Using the online STITCH database, we have found that lncRNA EGFR-AS1 has a positive interaction with PTBP1 and 
hnRNPs, major players in alternative splicing and essential for the generation of EGFR-A isoform with both transmembrane and tyrosine kinase domain.

Since the last decade, non-coding RNAs have been one of the main focuses in the field of functional genomics. Emerging evidence has shown the altered expression signatures of a large number of lncRNAs in several human malignancies ${ }^{24}$. In recent years, many of lncRNAs have been proposed to have pivotal role in carcinogenesis. However, the functions and mechanisms of lncRNAs responsible for the development and progression of oral cancer need to be understood. Natural antisense transcripts (NATs) are a group of RNA transcripts that are suggested to play roles in alternative splicing, genomic imprinting, miRNA sponging, also $\mathrm{X}$ - chromosome inactivation and they regulate the gene expression both in cis- and trans- manner ${ }^{25-27}$. cis-NAT plays major role in regulation of its sense partner in various manners. A myriad of lncRNA comes under this class of RNA and various studies reported their cis role. Recently, we reported a cis- mediated regulation of OIP5-AS1 controlling expression of OIP5 gene by acting as miRNA sponge ${ }^{28}$. Various pan cancer analysis showed the role of deregulated NATs in carcinogenesis and acting as both predictive marker as well as drug targets ${ }^{29}$.

EGFR-AS1, a lncRNA transcribed from the antisense strand of EGFR, was found to be overexpressed in several cancers ${ }^{30,11,31-33}$. Our study observed a significant upregulation of EGFR-AS1 in oral cancer patients suggesting the oncogenic potential of this lncRNA, which is consistent with above findings. When the EGFR-AS1 expression profile was analysed with reference to genotypes we found a decreased expression of EGFR in GG compared to GA+AA genotype, but without any statistical significance. The altered expression pattern of EGFR-AS1 might be due to previously reported non-canonical RNA editing mechanism which maintains the allele specific lncRNA based on germline polymorphism ${ }^{34}$.

In this study, there was a significant change in the EGFR D:A isoform ratio with the low level expression of EGFR-AS1. Alternative splicing of receptor tyrosine kinases (RTKs) has greater clinical implication, where truncated RTKs arise by alternative splicing of exons or activation of intronic polyA sites ${ }^{35}$. These truncated forms lack transmembrane and tyrosine kinase domain and thus can be used as a good prognostic marker ${ }^{6}$. EGFR has three different soluble truncated isoforms such as $110 \mathrm{kDa}, 80 \mathrm{kDa}$ and $60 \mathrm{kDa}$ where EGFR D form (110 kDa) is highly expressed in human placenta ${ }^{15}$ and found to be enriched in urine of patients with squamous cell 
239 carcinoma $^{36}$. Several studies reported the prognostic values of these soluble EGFR in various 240 cancers $^{37-40}$.

241 Our bioinformatic analysis revealed that premature termination of EGFR transcript results in the 242 production of EGFR-D isoform by recognition of intronic polyA (IPA) sites and activating 243 premature cleavage and polyadenylation. Additionally, our biomining approach discovered the 244 RNA binding proteins such as PTBP1 and hnRNPU, which were known to play an important role in alternate splicing by significantly interacting with EGFR-AS1. The binding sites for these proteins were present in the skipped exons $15 \mathrm{a}$ and $15 \mathrm{~b}$, which resides between exons 15 and 16 of EGFR. Previous studies have shown that PTBP1 overexpression was known to function as splicing silencer of exon 3 of BIM gene by binding to its intron $2^{41}$ and was also known to act as a splicing reprogrammer of $P K M$ gene in pancreatic cancer ${ }^{42}$. Additionally, PTBP1 and PTBP2 are larger family of non-conserved cryptic exons repressors ${ }^{43}$.

Previous studies have established that SNRNPA (U1snRNP) prevents the formation of truncated RTK isoforms by negatively controlling the use of IPA sites ${ }^{35}$. Surprisingly, STITCH analysis showed that PTBP1 has a mechanical interaction with SNRNPA which indicates the role of PTBP1 in regulating RTKs isoforms. Besides these several studies emphasized the role of chromatin signatures in alternative splicing Luco et al., reported the role of $\mathrm{H} 3 \mathrm{~K} 36 \mathrm{me} 3$ in recruiting PTBP1 in FGFR exon $3 \mathrm{~b}$ and promotes alternative splicing of exon $3 \mathrm{c}$ in mesenchymal cells ${ }^{44}$. Our analysis for chromatin signatures using UCSC genome browsers showed that EGFR exon 15a region is enriched with H3K36me3 mark supporting their role in alternative splicing through PTBP1. Earlier study reported that HuR binding proteins promote alternative splicing of NF1 and FAS transcripts by inducing localized histone hyperacetylation ${ }^{45}$. Recent finding identified EGFR-AS1 and HuR interaction suggesting its role in controlling alternative splicing via chromatin modification ${ }^{32}$. These observations collectively suggest the role of EGFR-AS1 in controlling the expression of EGFR-A from suppressing the formation of EGFR-D.

Certain lncRNAs were shown to competitively sponge the miRNAs and protects its protein 266 coding RNA partners from miRNA mediated repression and modulate their stability. This ceRNA hypothesis is one such phenomenon by which NATs may modulate cis regulation in controlling the expression of its sense partner ${ }^{46}$. Our biomining revealed that this germline variant $r$ s 10251977 in EGFR-AS1 regulates the stability of the lncRNA by miRNA mediated 
degradation. The minor allele generates a new binding site for miR-891b and resulting in diminished level of EGFR-AS1. This is evident from our results that the decreased level of EGFR-AS1 in tumors that expressed high level of miR-891b. Interestingly, we also found that miR-891b binding site was found in 3'UTR of EGFR-A isoform. We also analyzed another miRNA, miR-138-5p whose binding site is present in both EGFR-AS1 and EGFR-A isoform and its high expression level correlated with reduced level of EGFR-AS1 and EGFR-A. Our study showed both miRNAs were tumor suppressors and downregulated in tumor samples. In addition to support the ceRNA function, recent studies have reported miRNA sponging activity of EGFR-AS $1^{47,33}$ and miR-891b mediated gene regulation ${ }^{48-50}$.

The above findings suggest that EGFR-AS1, promotes tumorigenesis by increasing the level of EGFR-A through the modulation of alternative splicing by preventing the premature termination through PTBP1. The germline polymorphism rs10251977 (G>A) in EGFR-AS1 creates binding site for miR-891b which decreases the level of EGFR-AS1 and thereby increasing the EGFR-D/A ratio which confers the susceptibility in tumor by promoting the EGFR-AS1 to act as miRNA sponge. These findings provide an insight on functional importance of germline polymorphism rs10251977 (G>A) in EGFR-AS1 and orchestrated interactions between noncoding RNAs and coding RNA in maintaining cellular homeostasis and its dysregulation may lead to development of cancer.

\section{Methods and materials}

\section{Clinical specimens}

The present study was conducted after the approval by the Institutional Ethics Committees (IEC) of Madras Medical College, Chennai (No.04092010) and Government Arignar Anna Memorial Cancer Hospital, Kancheepuram (No.101041/e1/2009-2) and also within the ethical framework of Dr. ALM PG Institute of Basic Medical Sciences, Chennai. The study includes a total of 180 participants diagnosed with OSCC and 184 healthy controls. Blood samples were collected to study the germline variant in EGFR. Forty-eight tumor tissue samples and eight normal tissues from individuals free from cancer were collected for expression studies. The patient's contextual and clinicopathological characteristics were documented with standard questionnaire following the IEC guidelines and written informed consent was obtained from each patient, after explaining 
about the research study. The tissues were collected in RNAlater solution (Ambion, USA) and transported to the laboratory in cold-storage and stored at $-80^{\circ} \mathrm{C}$.

\section{DNA isolation}

The blood samples were subjected for DNA isolation using Proteinase K digestion and PCI extraction method. The isolated DNA was quantified using NanoDrop2000 UV-Vis spectrophotometer (Thermo Scientific, USA) and its integrity was assessed by resolving in $1 \%$ agarose gel in Mupid gel electrophoresis (TaKaRa, Japan) and diluted to 100ng/ $\mu \mathrm{L}$ stored at $20^{\circ} \mathrm{C}$ which was later used for screening germline variants.

\section{PCR amplification and sequencing of germline variant rs10251977 in EGFR}

The exon 20 of EGFR gene harbouring the SNP was amplified from 364 DNA samples (180 oral cancer patients and 184 healthy controls) using the sequence specific primers EGFR Fwd:5'- M13- CCTTCTGGCCACCATGCGAA-3' and Rev:5'-CGCATGTGAGGATCC TGGCT -3' (where M13 in the EGFR Fwd is the universal sequencing primer $5^{\prime}$ - tgtaaaacgacggccagt $\left.-3^{\prime}\right)$. Polymerase chain reaction (PCR) was carried in $30 \mu \mathrm{L}$ volume containing 100ng of genomic DNA, $1 \mathrm{X}$ PCR buffer, $1.5 \mathrm{mM} \mathrm{MgCl}_{2}, 100 \mu \mathrm{M}$ dNTP (Takara, Japan), 80nM primers (Sigma India) and 0.5U of Takara Taq polymerase (Takara, Japan). The PCR is performed using the following thermal conditions: $94^{\circ} \mathrm{C}$ for $2 \mathrm{~min}$ for initial denaturation, followed by $40 \mathrm{cycles}$ of $94^{\circ} \mathrm{C}$ for $30 \mathrm{sec}, 60^{\circ} \mathrm{C}$ for $30 \mathrm{sec}$ and $72^{\circ} \mathrm{C}$ for $30 \mathrm{sec}$, and $7 \mathrm{~min}$ of final extension at $72^{\circ} \mathrm{C}$. The PCR products (298 bp) were electrophoresed in $2 \%$ agarose gel. The purified PCR products were sequenced at Macrogen Inc, South Korea.

\section{RNA isolation and quality control}

The tumor samples soaked in RNA later solutions and frozen in $-80^{\circ} \mathrm{C}$ were thawed on ice, washed twice with 1x ice cold PBS, homogenized with zirconium beads using MicroSmash MS-100 automated homogenizer (Tomy Digital Biology, Japan). The total RNA was isolated using the RNAeasy mini kit (Qiagen, Germany) following the manufacturer's protocol. RNA was quantified using NanoDrop2000 UV-Vis spectrophotometer (Thermo Scientific, USA) and the RNA integrity was assessed by resolving in DEPC treated 1\% agarose gel in Mupid gel electrophoresis (TaKaRa, Japan). 
329 The cDNA conversion was carried out from total RNA using custom designed miRNA seed specific stem-loop primers for miRNAs (Table S5) and a random hexamer primer for coding/ non-coding RNAs, with $2 \mu \mathrm{g}$ of RNA for mRNA and lncRNAs and 10ng of RNA for miRNAs. The RNA samples were pre-incubated at $65^{\circ} \mathrm{C}$ for $20 \mathrm{~min}$ followed by $55^{\circ} \mathrm{C}$ for $90 \mathrm{~min}, 72^{\circ} \mathrm{C}$ for 15 min and final hold at $4^{\circ} \mathrm{C}$. cDNA conversion was performed using a Reverse Transcription kit (Invitrogen; Thermo Fisher Scientific, Inc. USA) and cDNAs were further diluted 25-fold and stored at $-20^{\circ} \mathrm{C}$.

Real-time RT-qPCR was performed in ABI Quantstudio 6 Flex (ABI Lifetechnology, USA). The reactions were performed in 384 well optical plates with $10 \mu l$ total volume using $1 \mu 1$ of cDNAs as template, TaqMan ${ }^{\circledR} 2 \mathrm{X}$ Universal Master mix (No AmpErase ${ }^{\circledR}$ UNG; Thermo Fisher Scientific, Inc. USA), specific forward primers (Table S6), universal reverse primer 5'-TCGTATCCAGTGCGTCGA GT -3', and fluorescein amidite-labeled minor groove binder probes 5'-CAGAGCCACCTGGGCAATTTT-3' for miRNAs expression. The EGFR A/D isoforms and EGFR-AS1 expression levels were analyzed using SYBR-Green master mix (KAPA SYBR FAST qPCR Kits, USA) with the gene specific primers (Table S7), by following the thermal cycling conditions: $50^{\circ} \mathrm{C}$ for $2 \mathrm{~min}$ and $95^{\circ} \mathrm{C}$ for $10 \mathrm{~min}$ once, followed by $95^{\circ} \mathrm{C}$ for $15 \mathrm{sec}$ and $60^{\circ} \mathrm{C}$ for $1 \mathrm{~min}$ for 40 cycles. GAPDH served as an endogenous control for coding and non-coding genes, and RNU44 as an endogenous control for miRNA. NTC reactions were used in all the experiments. All the reactions were carried out in triplicates, mean $\mathrm{Ct}$ was used for analysis and the expression level was calculated using $2^{-\Delta \Delta \mathrm{Ct}}$ method.

\section{In-silico approaches}

To predict the proteins interacting with EGFR-AS1, IncRNAtor $^{12}$ an online database was used and consensus motifs were predicted using the RBPMap ${ }^{13}$ to identify the RNA binding partners and motifs of interest such as PTBP1 in both EGFR-AS1 and skipped exons of EGFR. The motifs with highest stringency were selected for the study. The STITCH online tool was used to collect the molecular partners for PTBP1. UCSC genome browser was used to visualize the epigenetic signal that promotes alternative splicing and also polyA sites to predict premature termination. To assess the functional impact of the polymorphism rs 10251977 in EGFR-AS1, lncRNASNP2 tool was used to identify the loss or creation of binding site for miRNA in the lncRNA or the structural impact on lncRNA was analysed. Gene targets of the miRNA were 
identified by Targetscan and MiRwalk online tools. Gene Set Enrichment Analysis (GSEA) done by MiRwalk web interface to understand the molecular pathways affected by the selected miRNAs.

\section{Statistical analysis}

The frequency of alleles and genotypes were compared between the patient's and control groups by chi-square test. Fisher exact test and odds ratio (OR) with $95 \%$ confidence interval (CI) was calculated to find the risk association. Differences between the means were presented as mean \pm SEM and analysed using Student's $t$-test (Mann-Whitney) using Graph Pad Prism statistical software, v 6.01 (Graph Pad software Inc, USA). All tests were two-tailed and a $p$ value of $<0.05$ was considered as statistically significant.

\section{References:}

Bray, F. et al. Global cancer statistics 2018: GLOBOCAN estimates of incidence and mortality worldwide for 36 cancers in 185 countries. CA: a cancer journal for clinicians 68, 394-424 (2018). Bose, P., Brockton, N. T. \& Dort, J. C. Head and neck cancer: from anatomy to biology. International journal of cancer 133, 2013-2023 (2013).

3 Arunkumar, G. et al. Expression profiling of long non-coding RNA identifies linc-RoR as a prognostic biomarker in oral cancer. Tumor Biology 39, 1010428317698366 (2017).

Elferink, L. A. \& Resto, V. A. Receptor-tyrosine-kinase-targeted therapies for head and neck cancer. Journal of signal transduction 2011 (2011).

5 Nagalakshmi, K., Jamil, K., Pingali, U., Reddy, M. V. \& Attili, S. S. Epidermal growth factor receptor (EGFR) mutations as biomarker for head and neck squamous cell carcinomas (HNSCC). Biomarkers 19, 198-206 (2014).

6 Tan, D. S. et al. Long noncoding RNA EGFR-AS1 mediates epidermal growth factor receptor addiction and modulates treatment response in squamous cell carcinoma. Nature medicine 23, 1167 (2017).

Sawicka, K., Bushell, M., Spriggs, K. A. \& Willis, A. E. Polypyrimidine-tract-binding protein: a multifunctional RNA-binding protein. Biochemical Society Transactions 36, 641-647 (2008).

Lin, J.-C., Tsao, M.-F. \& Lin, Y.-J. Differential impacts of alternative splicing networks on apoptosis. International journal of molecular sciences 17, 2097 (2016).

Albitar, L. et al. EGFR isoforms and gene regulation in human endometrial cancer cells. Molecular cancer 9, 1-13 (2010). 
$390 \quad 10$

391

$392 \quad 11$

393

$394 \quad 12$

395

396

397

398

399

400

401

402

$403 \quad 16$

404

405

406

407

408

409

410

411

$412 \quad 20$

413

$414 \quad 21$

415

$416 \quad 22$

417

$418 \quad 23$

419

420

$421 \quad 24$

422

Weinholdt, C. et al. Prediction of regulatory targets of alternative isoforms of the epidermal growth factor receptor in a glioblastoma cell line. BMC bioinformatics 20, 434 (2019).

$1 \mathrm{Hu}$, J. et al. Long noncoding RNA EGFR-AS1 promotes cell proliferation by increasing EGFR mRNA stability in gastric cancer. Cellular Physiology and Biochemistry 49, 322-334 (2018).

12 Park, C., Yu, N., Choi, I., Kim, W. \& Lee, S. IncRNAtor: a comprehensive resource for functional investigation of long non-coding RNAs. Bioinformatics 30, 2480-2485 (2014).

13 Paz, I., Kosti, I., Ares Jr, M., Cline, M. \& Mandel-Gutfreund, Y. RBPmap: a web server for mapping binding sites of RNA-binding proteins. Nucleic acids research 42, W361-W367 (2014).

14 Brown, S. J., Stoilov, P. \& Xing, Y. Chromatin and epigenetic regulation of pre-mRNA processing. Human molecular genetics 21, R90-R96 (2012).

15 Abou-Fayçal, C., Hatat, A.-S., Gazzeri, S. \& Eymin, B. Splice variants of the RTK family: their role in tumour progression and response to targeted therapy. International journal of molecular sciences 18, 383 (2017).

16 Schlessinger, J. Receptor tyrosine kinases: legacy of the first two decades. Cold Spring Harbor perspectives in biology 6, a008912 (2014).

17 Sigismund, S., Avanzato, D. \& Lanzetti, L. Emerging functions of the EGFR in cancer. Molecular oncology 12, 3-20 (2018).

$18 \mathrm{Mu}, \mathrm{X}$. L. et al. Gefitinib-sensitive mutations of the epidermal growth factor receptor tyrosine kinase domain in Chinese patients with non-small cell lung cancer. Clinical cancer research 11, 4289-4294 (2005).

19 Sasaki, H. et al. EGFR polymorphism of the kinase domain in Japanese lung cancer. Journal of Surgical Research 148, 260-263 (2008).

20 Leichsenring, J. et al. Synonymous EGFR variant p. Q787Q is neither prognostic nor predictive in patients with lung adenocarcinoma. Genes, Chromosomes and Cancer 56, 214-220 (2017).

21 Bonin, S. et al. A synonymous EGFR polymorphism predicting responsiveness to anti-EGFR therapy in metastatic colorectal cancer patients. Tumor Biology 37, 7295-7303 (2016).

22 Koh, Y. W. et al. Q787Q EGFR polymorphism as a prognostic factor for lung squamous cell carcinoma. Oncology 90, 289-298 (2016).

Wang, W.-P., Wang, K.-N., Gao, Q. \& Chen, L.-Q. Lack of EGFR mutations benefiting gefitinib treatment in adenocarcinoma of esophagogastric junction. World Journal of Surgical Oncology 10, 14 (2012).

24 Bolha, L., Ravnik-Glavač, M. \& Glavač, D. Long noncoding RNAs as biomarkers in cancer. Disease markers 2017 (2017). 
42325 He, Y., Vogelstein, B., Velculescu, V. E., Papadopoulos, N. \& Kinzler, K. W. The antisense $424 \quad$ transcriptomes of human cells. Science 322, 1855-1857 (2008).

42526 Lindsay, M. A., Griffiths-Jones, S., Wight, M. \& Werner, A. The functions of natural antisense transcripts. Essays in biochemistry 54, 91-101 (2013). Wenric, S. et al. Transcriptome-wide analysis of natural antisense transcripts shows their potential role in breast cancer. Scientific reports 7, 1-12 (2017).

Arunkumar, G. et al. LncRNA OIP5-AS1 is overexpressed in undifferentiated oral tumors and integrated analysis identifies as a downstream effector of stemness-associated transcription factors. Scientific reports 8, 1-13 (2018). genes in each tumor context. Cell reports 23, 297-312. e212 (2018).

Qi, H.-l. et al. The long noncoding RNA, EGFR-AS1, a target of GHR, increases the expression of EGFR in hepatocellular carcinoma. Tumor Biology 37, 1079-1089 (2016). Dong, Z.-Q., Guo, Z.-Y. \& Xie, J. The IncRNA EGFR-AS1 is linked to migration, invasion and apoptosis in glioma cells by targeting miR-133b/RACK1. Biomedicine \& Pharmacotherapy 118, 109292 (2019).

Wang, A. et al. Long noncoding RNA EGFR-AS1 promotes cell growth and metastasis via affecting HuR mediated mRNA stability of EGFR in renal cancer. Cell death \& disease 10, 1-14 (2019). Xu, Y.-H., Tu, J.-R., Zhao, T.-T., Xie, S.-G. \& Tang, S.-B. Overexpression of IncRNA EGFR-AS1 is associated with a poor prognosis and promotes chemotherapy resistance in non-small cell lung cancer. International journal of oncology 54, 295-305 (2019).

Shah, M. Y. et al. Cancer-associated rs6983267 SNP and its accompanying long noncoding RNA CCAT2 induce myeloid malignancies via unique SNP-specific RNA mutations. Genome research 28, 432-447 (2018).

Vorlová, S. et al. Induction of antagonistic soluble decoy receptor tyrosine kinases by intronic polyA activation. Molecular cell 43, 927-939 (2011). factor receptor-like protein (TEGFR) in ovarian cancer. Gynecologic oncology 65, 36-41 (1997).

37 Jantus-Lewintre, E. et al. Analysis of the Prognostic Value of Soluble Epidermal Growth Factor Receptor Plasma Concentration in Advanced Non-Small-Cell Lung Cancer Patients. Clinical lung cancer 12, 320-327 (2011).

38 Guillaudeau, A. et al. EGFR soluble isoforms and their transcripts are expressed in meningiomas. PLoS One 7, e37204 (2012). 
Zampino, M. et al. Epidermal growth factor receptor serum (sEGFR) level may predict response in patients with EGFR positive advanced colorectal cancer treated with gefitinib? Cancer chemotherapy and pharmacology 63, 139-148 (2008).

40 MÜLLER, V. et al. Prognostic and predictive impact of soluble epidermal growth factor receptor (sEGFR) protein in the serum of patients treated with chemotherapy for metastatic breast cancer. Anticancer research 26, 1479-1487 (2006).

41 Juan, W. C., Roca, X. \& Ong, S. T. Identification of cis-acting elements and splicing factors involved in the regulation of BIM Pre-mRNA splicing. PLoS One 9, e95210 (2014).

42 Calabretta, S. et al. Modulation of PKM alternative splicing by PTBP1 promotes gemcitabine resistance in pancreatic cancer cells. Oncogene 35, 2031-2039 (2016).

43 Ling, J. P. et al. PTBP1 and PTBP2 repress nonconserved cryptic exons. Cell reports 17, 104-113 (2016).

44 Luco, R. F. et al. Regulation of alternative splicing by histone modifications. Science 327, 9961000 (2010).

45 Zhou, H.-L. et al. Hu proteins regulate alternative splicing by inducing localized histone hyperacetylation in an RNA-dependent manner. Proceedings of the National Academy of Sciences 108, E627-E635 (2011).

6 Kulkarni, A., Anderson, A. G., Merullo, D. P. \& Konopka, G. Beyond bulk: a review of single cell transcriptomics methodologies and applications. Current opinion in biotechnology 58, 129-136 (2019).

47 Feng, Z. et al. LncRNA EGFR-AS1 upregulates ROCK1 by sponging miR-145 to promote Esophageal squamous cell carcinoma cell invasion and migration. Cancer Biotherapy \& Radiopharmaceuticals 35, 66-71 (2020).

48 Belleannée, C. et al. Role of microRNAs in controlling gene expression in different segments of the human epididymis. PloS one 7, e34996 (2012).

49 Dong, Q. et al. MicroRNA-891b is an independent prognostic factor of pancreatic cancer by targeting Cbl-b to suppress the growth of pancreatic cancer cells. Oncotarget 7, 82338 (2016).

$50 \mathrm{Xu}, \mathrm{S}$. et al. Down-regulation of PARP1 by miR-891b sensitizes human breast cancer cells to alkylating chemotherapeutic drugs. Archives of gynecology and obstetrics 296, 543-549 (2017). 
493

494

495

496

497

498

499

500

501

502

503

504

505

506

508

509

510

511

512

513

514

515

516

517

507

\section{Acknowledgement}

We were very grateful for the patients agreeing to provide clinical samples for this study. SD and MMR acknowledge the research fellowship from University Grant Commission (UGC), Govt. of India. The study was supported by grants DHR- starter grant (No. V.25011/536-HRD/2016-HR), DHR, Government of India and NIG-JOINT(1A2019), Japan to Dr. A. K. Munirajan. We also gratefully acknowledge the DST-FIST, UGC-SAP and DHR-MRU infrastructural facility.

\section{Authors Contributions}

AKM (corresponding author) designed the study, supervised the experiments, data analysis and reviewed the manuscript. SD and MMR participated in study design, performed all the experiments, analyzed the data and wrote the manuscript. RCS assisted in study design, analysed the data and reviewed the manuscript. KVUD assisted the real-time PCR experiments and bioinformatics analysis. RA \& SS provided tumor samples and clinical data. II critically reviewed the manuscript. All authors read and approved the final manuscript.

\section{Competing interests}

The author declared that there are no competing interests.

3

4

5

6

08

9

1



a. Relative expression level of lncRNA EGFR-AS1 in oral tumors compared with normal tissues. b. Graph showing the relative fold change of EGFR A and D isoforms in relation to EGFR-AS1 high and low expression groups. c. Graph shows the EGFR D/A ratio in relation to EGFR high and low expression groups. (Statistical significance represented as p-value $* * * *$ for $<0.0001$, $* * *$ for $<0.001, *$ for $<0.01$, ns for non-significant, two tailed Student's t-test).

Figure 2 In-silico characterization of EGFR-AS1 role in alternative splicing of EGFR

a. STITCH analysis showing the binding partners of PTBP1. b. UCSC genome browser data shows the H3K36me3 marks (green box) and polyA sites (orange box) prevalence between exon 15 and 16 skipped region (blue box) of EGFR.

Figure 3 rs10251977 minor allele's effect on EGFR-AS1

a. Absence of minor allele in EGFR-AS1 (Blue arrow). b. Prediction of effect of minor allele in EGFR-AS1 generating binding site for miR-891b using lncRNASNP2 (Red arrow indicating presence of variant allele). c. Figure showing the binding site for another miRNA, miR-138-5p in EGFR-AS1. d. miRWalk database showing the targets of both miR-891b and miR-138-5p (EGFR encircled in both miRNAs).

\section{Figure 4 miR-891b sponging by EGFR-AS1 promoting the expression of EGFR-A isoform}

a. Graph showing the relative fold change of miR-891b. b. Graph showing the relative fold change of miR-138-5p. c. Graph shows the relative fold change of EGFR-AS1 in relation to miR-891b. d. Graph showing the relative fold change of EGFR-AS1 in relation to miR-138-5p levels. e. Graph shows the relative fold change of EGFR-AS1 in relation to miR-891b. (Statistical significance represented as * for $\mathrm{P}<0.01$, two tailed Student's t-test). Tables

Table 1 Demographic and clinical data of Oral cancer patients and healthy controls

\section{Table 2 Genotype and allele frequency in South Indian oral cancer patients and controls}


$551 \quad$ Figure $\mathbf{S 1}$

552 a. Graph showing the relative fold change of EGFR-AS1 in relation to clinicopathological

553 characteristics. b. Relative fold change of EGFR-AS1 in patients with GG and GA+ AA 554 genotype of $r$ s10251977.

$555 \quad$ Figure S2

556 a. Predicted EGFR-AS1 interacting proteins using online database lncRNAtor.

557 b. LncRNASNP2 showing the miRNA target sites, with miR-138-5p (within box) is targeted 558 independent of the variant $r s 10251977$.

$559 \quad$ Figure S3

560 a. Graph showing EGFR D/A ratio level in relation to miR-891b levels.

561 b. Graph showing EGFR D/A ratio level in relation to miR-138-5p levels.

Table S1 Table showing the prevalence of binding motif of PTBP1 in EGFR-AS1 using 564 RBPmap online tool

565 Table S2 Table showing the prevalence of binding motif of PTBP1 in EGFR 15 and 16 566 exons using RBPmap online tool

567 Table S3 miR-891b miRWalk_GSEA_results (Excel file)

568 Table S4 miR-138-5p miRWalk_GSEA_results (Excel file)

569 Table S5 List of Universal reverse transcription primers used for cDNA synthesis

570 Table S6 List of gene specific forward primers used for real time PCR experiments

571 Table S7 List of primers used for SYBR Green gene expression assays

572

573

574

575

576

577

578

579

580 
581 Figure.1

582

583

584

585

586

587

588

589

590

591

592

593

594

595

596

597

598

599

600

601

602

603

604

605

606

607

608

609

610

611

612 a
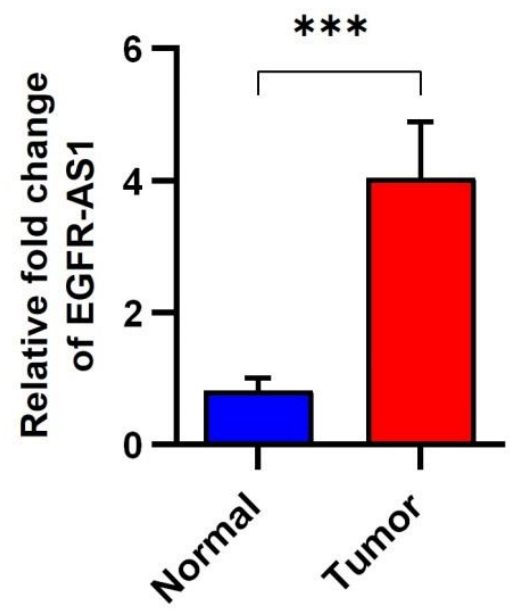

b
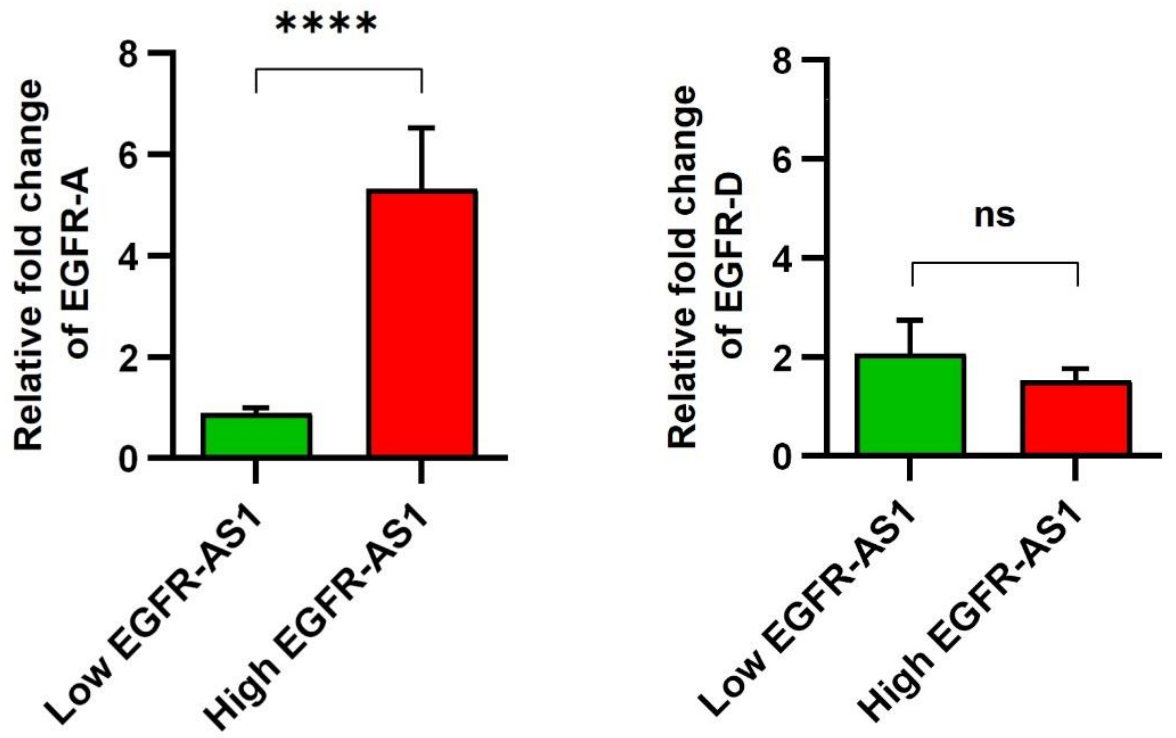

C
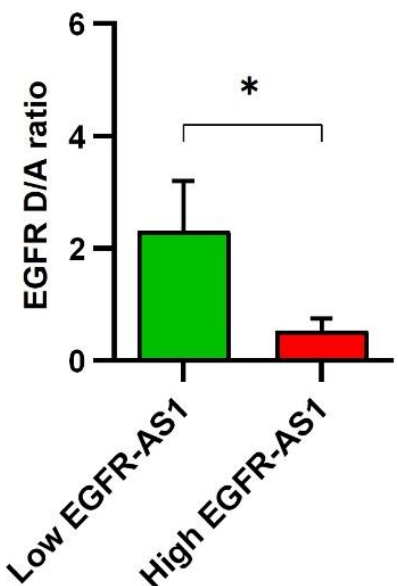


\section{$613 \quad$ Figure.2 \\ 614}

615

616

617

618

619

620

621

622

623

624

625

626

627

628

629

630

631

632

633

634

635

636

637

638

639

640

641

642

643

644 
651

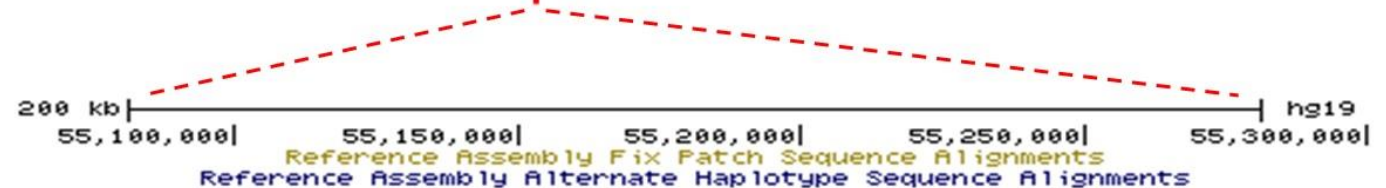

Reference Assembly Alternate Haplotype sequence Alignments

655

656

657

658

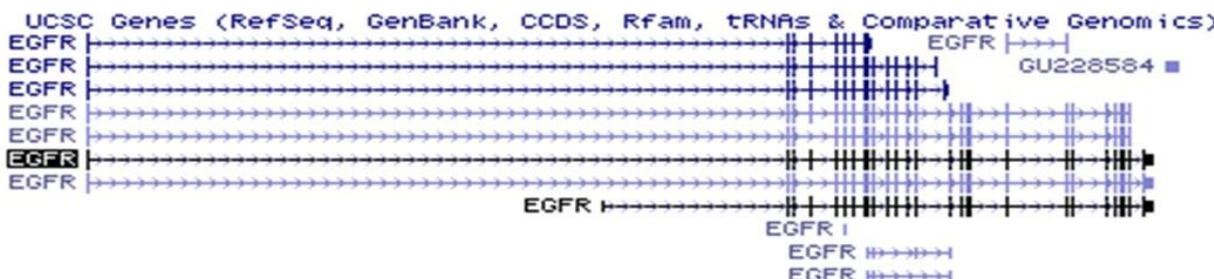

EGFR $H \rightarrow \rightarrow \rightarrow \rightarrow-1$

$$
\text { EGFR : }
$$

Reported Foly(A) Sites from POIYA_DB 


\section{Figure.3}

a

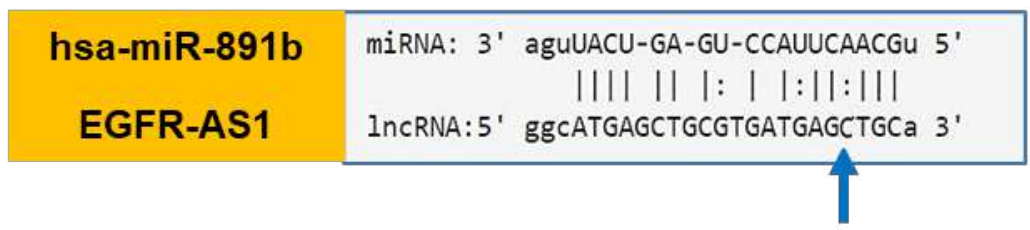

b

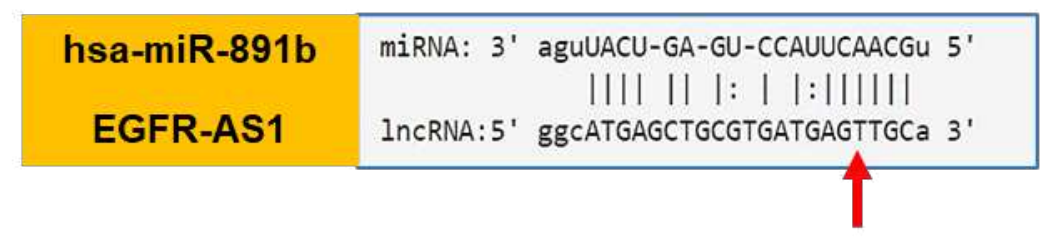

c

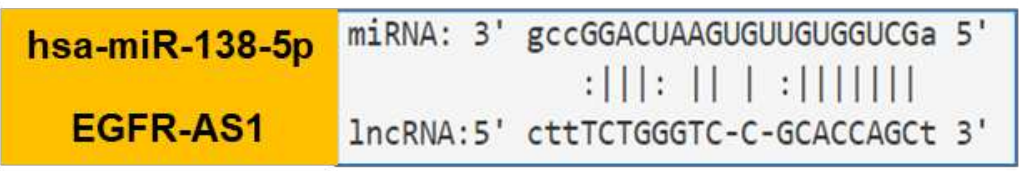

d

677

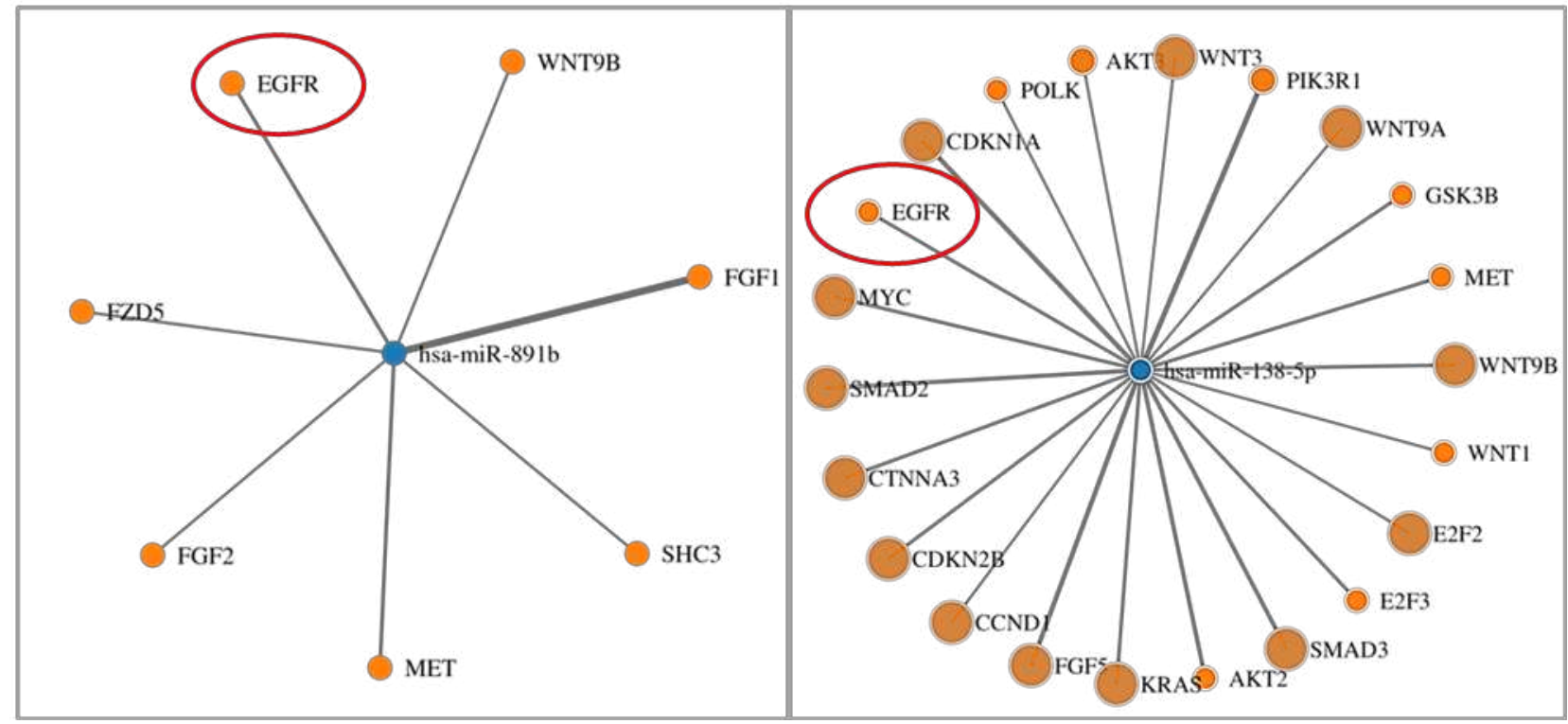

678

679

680

681

682 

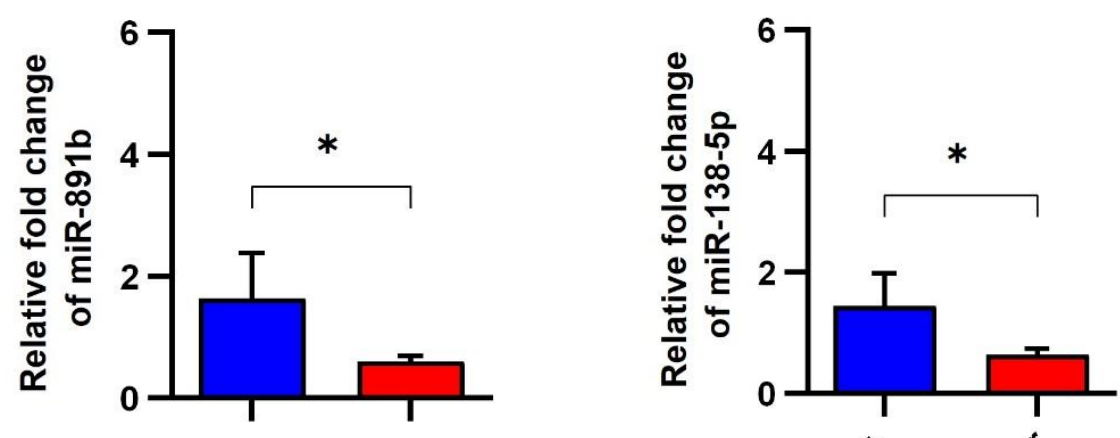

696

697

698

C

699

700

701

702

703

704

705

706

707

708

709

710

711

712

713

714
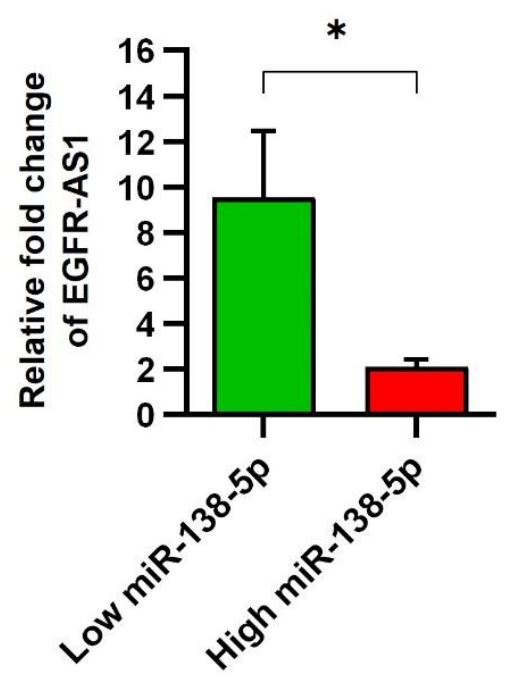

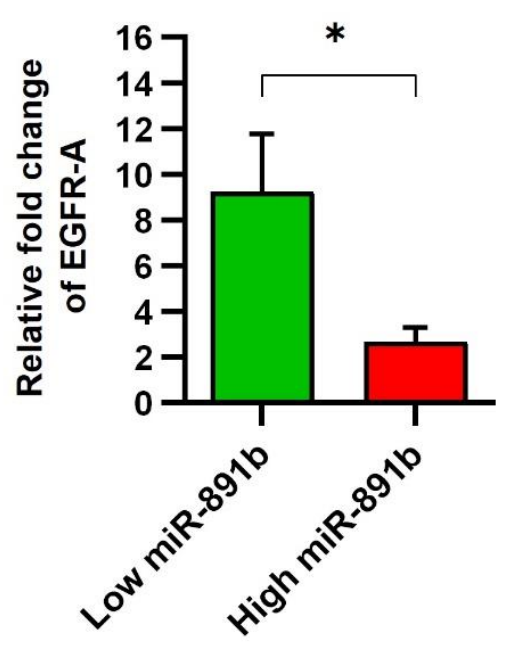


Table 1 Demographic and clinical data of Oral cancer patients and healthy controls

\begin{tabular}{|c|c|c|}
\hline Clinical parameters & $\begin{array}{l}\text { Oral cancer patients } \\
\qquad(\mathrm{n}=180)\end{array}$ & $\begin{array}{l}\text { Controls } \\
(n=184)\end{array}$ \\
\hline Age in years, Mean \pm SD & $53.1 \pm 11.0(26-80)$ & $50.4 \pm 9.3(25-82)$ \\
\hline Sex (Male / Female) & $124 / 56$ & $125 / 59$ \\
\hline \multicolumn{3}{|l|}{ Risk habits $\mathbf{N}(\%)$} \\
\hline Smoking & $96(53.3)$ & $9(4.9)$ \\
\hline Chewing & $75(41.6)$ & - \\
\hline Alcoholics & $46(25.5)$ & $4(2.2)$ \\
\hline Smoking + chewing & $25(13.8)$ & - \\
\hline Smoking + alcoholics & $16(8.8)$ & $55(29.9)$ \\
\hline Smoking + chewing +alcoholics & $19(10.5)$ & - \\
\hline No risk habits & $42(23.3)$ & $116(63)$ \\
\hline \multicolumn{3}{|l|}{$\begin{array}{c}\text { Histological differentiation } \\
\qquad \mathrm{N}(\%)\end{array}$} \\
\hline Poor & $26(14.4)$ & - \\
\hline Moderate & $77(42.8)$ & - \\
\hline Well & $77(42.8)$ & - \\
\hline \multicolumn{3}{|l|}{ Tumor Stage N (\%) } \\
\hline$\leq \mathrm{T} 2$ & $34(18.9)$ & - \\
\hline$>\mathrm{T} 2$ & $146(81.1)$ & - \\
\hline \multicolumn{3}{|l|}{ Nodal invasion $\mathbf{N}(\%)$} \\
\hline Positive & $150(83.3)$ & - \\
\hline Negative & $30(16.7)$ & - \\
\hline
\end{tabular}


Table2 Genotype, Allele frequency in South Indian oral cancer patients and controls

\begin{tabular}{|c|c|c|c|c|c|c|}
\hline \multicolumn{2}{|c|}{ rs10251977; c.2361G>A } & $\begin{array}{c}\text { Oral Cancer } \\
\mathbf{N}(\%) \\
\end{array}$ & $\begin{array}{c}\text { Control } \\
\mathbf{N}(\%) \\
\end{array}$ & $\begin{array}{l}\text { Odds } \\
\text { ratio } \\
\end{array}$ & $95 \% \mathrm{CI}$ & $\begin{array}{c}\text { p- } \\
\text { value }\end{array}$ \\
\hline \multirow{3}{*}{ Genotype } & GG & $72(40)$ & $67(36.4)$ & 1 (Ref) & & \\
\hline & GA & $85(47.2)$ & $93(50.5)$ & 1.17 & $0.75-1.83$ & 0.47 \\
\hline & $\mathrm{AA}$ & $23(12.8)$ & $24(13.1)$ & 1.12 & $0.57-2.17$ & 0.73 \\
\hline Dominant model & $\mathrm{GA}+\mathrm{AA}$ & $108(60)$ & $117(63.6)$ & 0.86 & $0.56-1.31$ & 0.55 \\
\hline Recessive model & $\mathrm{GG}+\mathrm{GA}$ & $157(87.2)$ & $160(87)$ & 0.98 & $0.53-1.80$ & 0.93 \\
\hline \multirow[t]{2}{*}{ Allelic model } & $\mathrm{G}$ & $229(63.6)$ & $227(61.7)$ & 1 (Ref) & & \\
\hline & $\mathrm{A}$ & $131(36.4))$ & $141(38.3)$ & 0.92 & $0.68-1.24$ & 0.64 \\
\hline \multicolumn{2}{|c|}{ HWE $\chi 2$} & 0.072 & 0.88 & & & \\
\hline \multicolumn{2}{|c|}{ HWE p-value } & 0.79 & 0.35 & & & \\
\hline
\end{tabular}


742

743

744 745

\begin{tabular}{|c|c|c|c|c|c|}
\hline \multirow{2}{*}{$\begin{array}{c}\text { Clinical } \\
\text { characteristics }\end{array}$} & \multicolumn{2}{|c|}{$\begin{array}{c}\text { EGFR-AS1 } \\
\text { expression level }\end{array}$} & \multirow{2}{*}{$\begin{array}{c}\text { p- } \\
\text { value }^{\#}\end{array}$} & \multirow[t]{2}{*}{ OR } & \multirow[t]{2}{*}{$95 \% \mathrm{CI}$} \\
\hline & $\begin{array}{c}\text { Low } \\
(\mathrm{N}=24)\end{array}$ & $\begin{array}{c}\text { High } \\
(\mathrm{N}=24)\end{array}$ & & & \\
\hline \multicolumn{6}{|l|}{ Age (Years) } \\
\hline$\leq \mathbf{5 1}$ & 11 & 14 & \multirow{2}{*}{0.5634} & \multirow{2}{*}{0.6044} & \multirow{2}{*}{$0.1929-1.893$} \\
\hline$>51$ & 13 & 10 & & & \\
\hline \multicolumn{6}{|l|}{ Sex } \\
\hline Female & 6 & 5 & \multirow{2}{*}{0.999} & \multirow{2}{*}{1.267} & \multirow{2}{*}{$0.3281-4.891$} \\
\hline Male & 18 & 19 & & & \\
\hline \multicolumn{6}{|l|}{ Tobacco habits } \\
\hline \multicolumn{6}{|l|}{ Smoking } \\
\hline Yes & 17 & 14 & \multirow{2}{*}{0.546} & \multirow{2}{*}{1.735} & \multirow{2}{*}{$0.5238-5.745$} \\
\hline No & 7 & 10 & & & \\
\hline \multicolumn{6}{|l|}{ Chewing } \\
\hline Yes & 10 & 10 & \multirow{2}{*}{0.7697} & \multirow{2}{*}{1} & \multirow{2}{*}{$0.3173-3.152$} \\
\hline No & 14 & 14 & & & \\
\hline \multicolumn{6}{|c|}{ Histological Differentiation } \\
\hline Poor and moderate & 17 & 14 & \multirow{2}{*}{0.546} & \multirow{2}{*}{1.735} & \multirow{2}{*}{$0.5238-5.745$} \\
\hline Well & 7 & 10 & & & \\
\hline \multicolumn{6}{|l|}{ Tumor Stage } \\
\hline$\leq \mathrm{T} 2$ & 3 & 8 & \multirow{2}{*}{0.831} & \multirow{2}{*}{0.8571} & \multirow{2}{*}{$0.1736-4.233$} \\
\hline$>\mathrm{T2}$ & 21 & 16 & & & \\
\hline \multicolumn{6}{|l|}{ Nodal invasion } \\
\hline Positive & 22 & 20 & \multirow{2}{*}{0.1905} & \multirow{2}{*}{2.2} & \multirow{2}{*}{$0.3627-13.34$} \\
\hline Negative & 2 & 4 & & & \\
\hline
\end{tabular}

Table 3 Relationship between EGFR-AS1 expression and clinicopathological characteristics in oral cancer patients. \#Fisher's exact test with two tailed $P$ value 
Figures

Figure.1

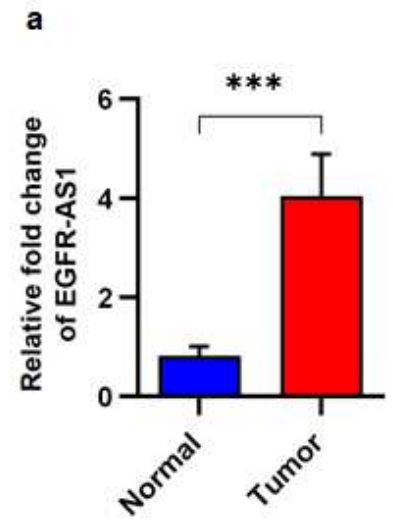

b
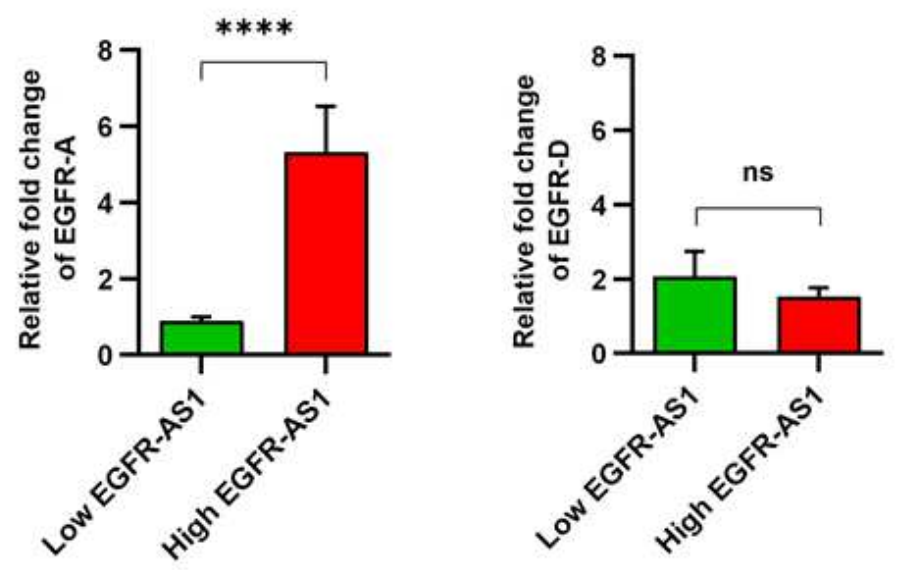

c

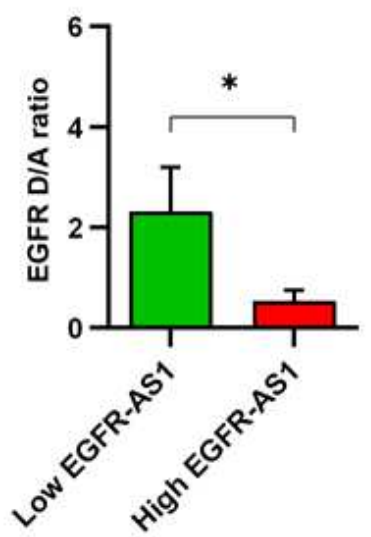

Figure 1

Role of EGFR-AS1 in maintaining the level of EGFR A and D isoforms in OSCC a. Relative expression level of IncRNA EGFR-AS1 in oral tumors compared with normal tissues. b. Graph showing the relative fold change of EGFR A and D isoforms in relation to EGFR-AS1 high and low expression groups. c. Graph 
shows the EGFR D/A ratio in relation to EGFR high and low expression groups. (Statistical significance

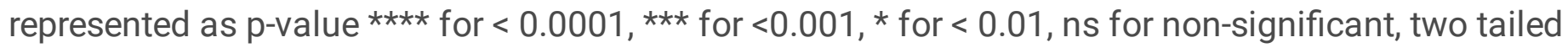
Student's t-test).

\section{Figure.2}

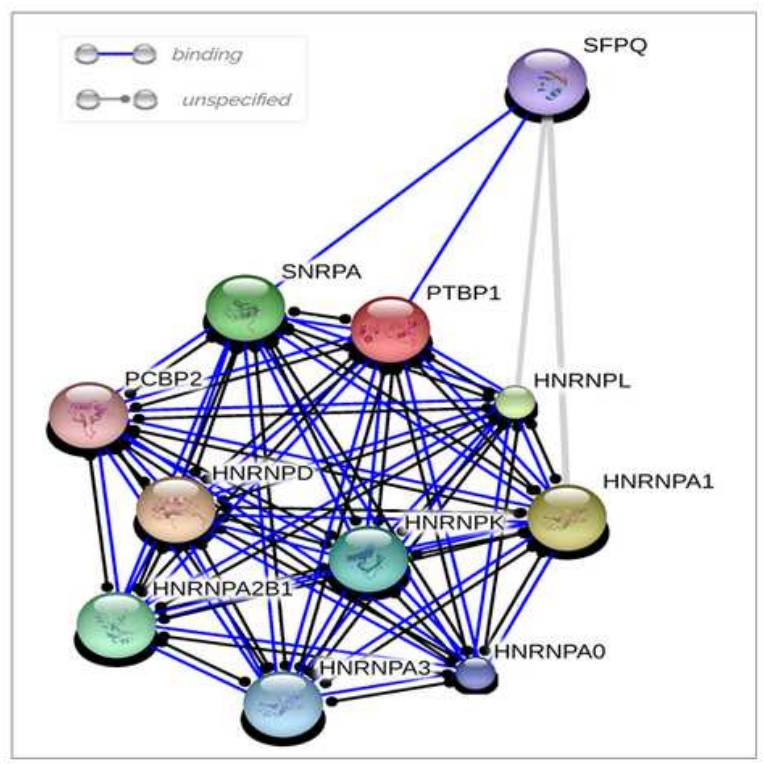

b

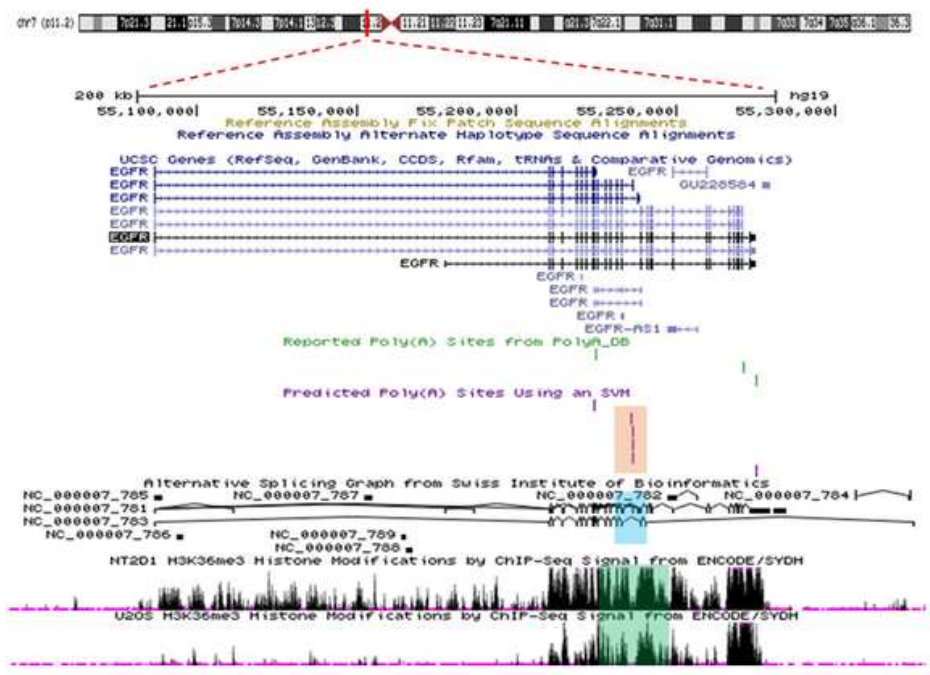

Figure 2

In-silico characterization of EGFR-AS1 role in alternative splicing of EGFR a. STITCH analysis showing the binding partners of PTBP1. b. UCSC genome browser data shows the H3K36me3 marks (green box) and polyA sites (orange box) prevalence between exon 15 and 16 skipped region (blue box) of EGFR. 


\section{Figure.3}

a

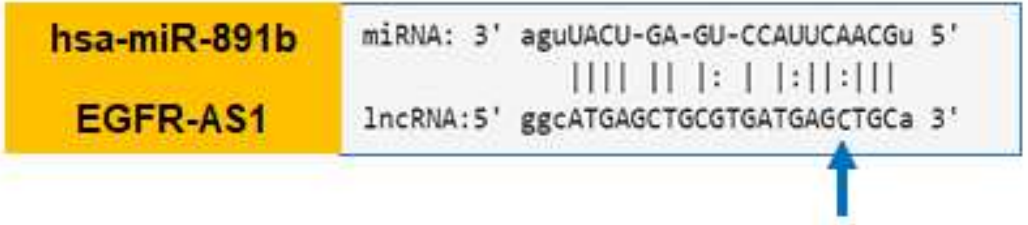

b

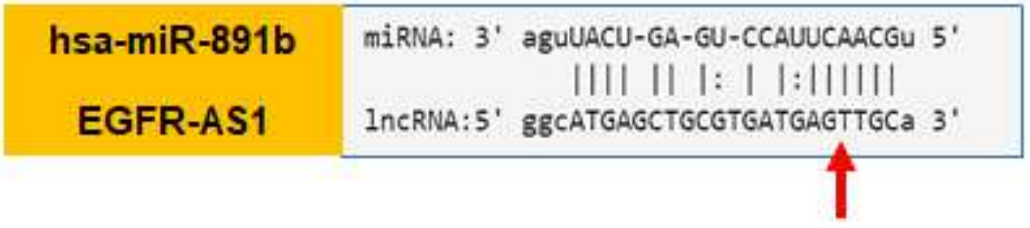

C

$\begin{array}{cc}\text { hsa-miR-138-5p } & \begin{array}{c}\text { miRNA: } 3^{\prime} \text { gcCGGACUAAGUGUUGUGGUCGa } 5^{\prime} \\ : \|||||||\end{array} \\ \text { EGFR-AS1 } & \text { InCRNA:5' cttTCTGGGTC-C-GCACCAGCt } 3^{\prime}\end{array}$

d

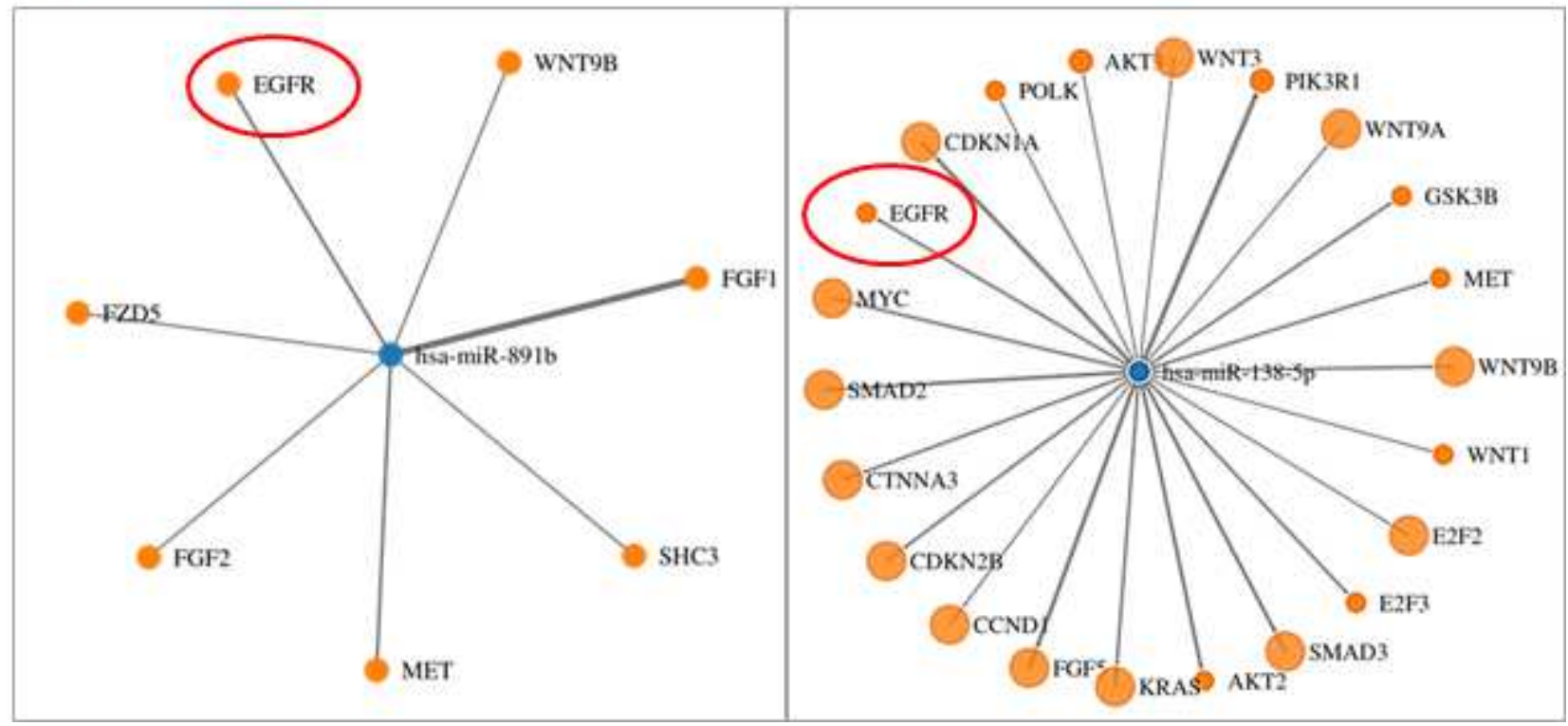

Figure 3

rs10251977 minor allele's effect on EGFR-AS1 529 a. Absence of minor allele in EGFR-AS1 (Blue arrow). b. Prediction of effect of minor allele in EGFR-AS1 generating binding site for miR-891b using IncRNASNP2 (Red arrow indicating presence of variant allele). c. Figure showing the binding site for another miRNA, miR-138-5p in EGFR-AS1. d. miRWalk database showing the targets of both miR-891b and miR-138-5p (EGFR encircled in both miRNAs). 
Figure.4

a

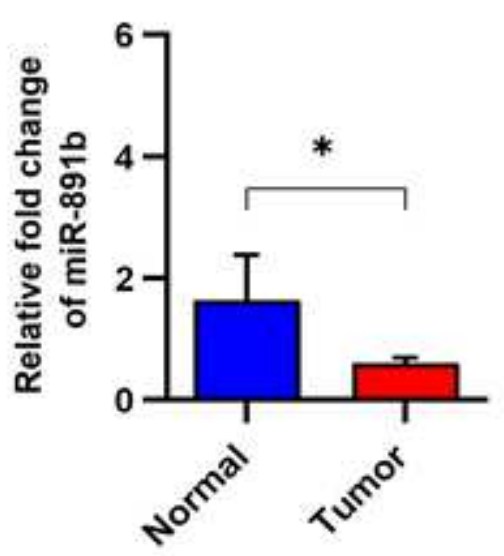

b

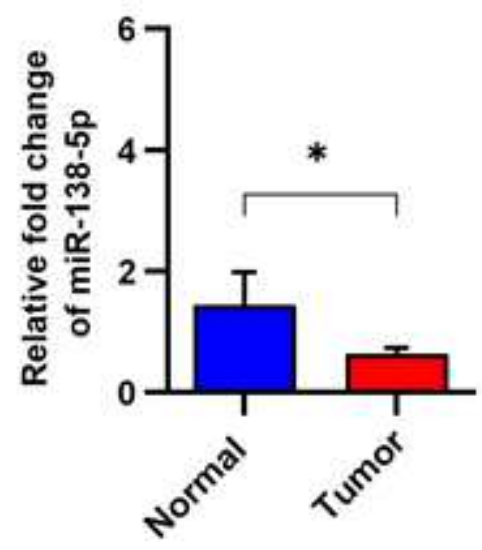

C

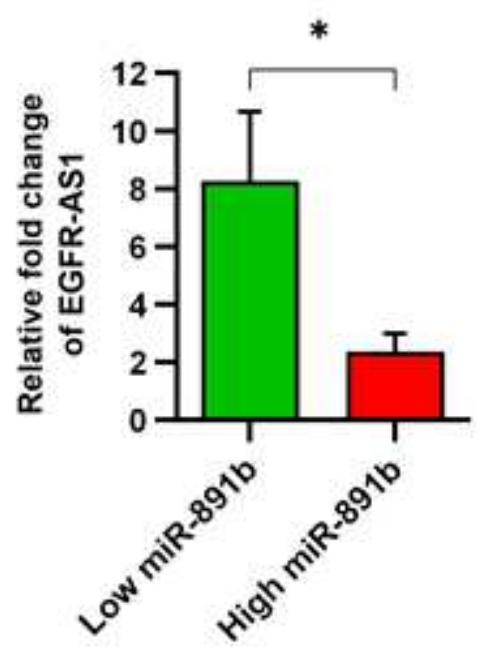

d

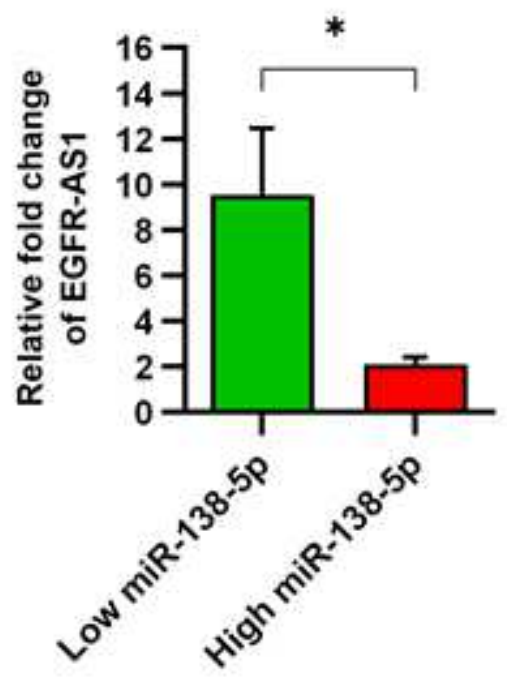

e

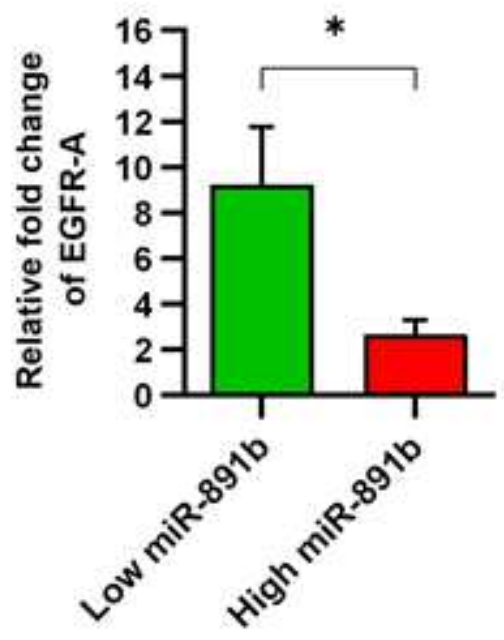

Figure 4

miR-891b sponging by EGFR-AS1 promoting the expression of EGFR-A isoform a. Graph showing the relative fold change of miR-891b. b. Graph showing the relative fold change of miR-138-5p. c. Graph shows the relative fold change of EGFR-AS1 in relation to miR-891b. d. Graph showing the relative fold change of EGFR-AS1 in relation to miR-138-5p levels. e. Graph shows the relative fold change of EGFRAS1 in relation to miR-891b. (Statistical significance represented as * for $P<0.01$, two tailed Student's ttest). 


\section{Supplementary Files}

This is a list of supplementary files associated with this preprint. Click to download.

- SupptableS4miR1385pmiRWalkGSEAresults.xls

- SupptableS3miR891bmiRWalkGSEAresults.xls

- SupplementarymaterialsEGFRAS1manuscript.docx 